\title{
The safety analysis of transportation vehicles carrying prefabricated units under the action of gusts
}

\author{
Gang Yao ${ }^{1,2}$, Mingpu Wang ${ }^{1,2}$ and Yang Yang ${ }^{1,2}$ \\ ${ }^{1}$ Key Laboratory of New Technology for Construction of Cities in Mountain Area, Ministry of Education, 400045 Chongqing, China \\ ${ }^{2}$ School of Civil Engineering, Chongqing University, 400045 Chongqing, China
}

\begin{abstract}
The prefabricated-unit industry has developed rapidly and the safety of vehicles carrying prefabricated units has received extensive attention. In order to evaluate the safety of vehicles carrying prefabricated units under the action of gusts, the roughness of road surfaces was simulated by the sinusoid superposition method. Furthermore, the wind load was simulated by the harmonic synthesis method. The analysis model of the 13-DOF vehicle was established, and the wind-vehicle-road system was formed. In addition, the safety of the vehicles carrying prefabricated units under gusts was analyzed. It is demonstrated that when a vehicle encounters a sudden gust during driving, lateral deviation of the body will occur. The contact force on the windward side wheel will drop sharply and the wheel is easy to get off the ground, which decides whether a rollover accident happens or not. It sheds light on the safety analysis for ultra-wide and overweight vehicles under gust action.
\end{abstract}

\section{Introduction}

The factory site of prefabricated units takes up a large area and is generally selected in a relatively remote area for cost reduction. It has a certain distance from the construction site and hence the number of relative transportation vehicles has been increasing in recent years. The prefabricated-unit plant has a reasonable haul distance of $70.0 \mathrm{~km}$ and the number of the transportation vehicles for prefabricated units in the radiating area increases. Prefabricated units are self-contained and large, and need ultra-wide and over-weight vehicles to transport. Therefore risk during driving is rapidly increased. Traffic safety is related to many factors such as vehicle type, road conditions, various loads acting on vehicle, and drivers' controllability [1]. At the same time, gusts have a greater impact on the vehicle safety [2].

Under the action of gust, if the speed limit of the vehicles carrying prefabricated units is too low or the passage is prohibited, there will be a negative impact on construction sites and prefabricated-unit plants. On the one hand, the original material entry plan of a construction site will be delayed, and then the entire progress of the construction site will be affected. What's more, if the transport path where the material enters the site involves traffic control, the road usage time must be re-applied, adding a lot of extra work. On the other hand, if the prefabricated units can't be transported out of the finished product yard of a prefabricated-unit factory in time, the production schedule of the factory will be delayed, resulting in the lag of subsequent production plan.
If there is no speed limit on the vehicles carrying prefabricated units under the action of gusts, the probability of traffic accidents would greatly augment. The transportation of prefabricated units is a newly arising issue from the development of prefabricated buildings. At present, the specifications for prefabricatedunit transport in China are incomplete, and there are few studies on the transportation safety of prefabricated units.

In summary, it is necessary to analyze the safety of vehicles carrying prefabricated units under the action of gusts. In this paper, the roughness of road surface was simulated by the sinusoid superposition method. The wind load was simulated by the harmonic synthesis method. The analysis model of the 13-DOF vehicle was established, and the wind-vehicle-road system was formed. Additionally, the safety of the vehicles carrying prefabricated units was analyzed with gusts.

\section{Wind-Vehicle-Road system}

\subsection{Wind load model}

At present, the Monte-Carlo random variable simulation method is widely used to simulate fluctuating wind speed, among which the wave superposition method is extensively applied because of its small error and good stability [3-7]. Hence, harmonic synthesis method was performed in this paper to simulate wind load where the cut-off frequency was $4.0 \mathrm{rad} / \mathrm{s}$, the frequency equivalent was 1024 , the sampling time interval was $0.25 \mathrm{~s}$, and the sampling time was $6.5 \mathrm{~s}$. Moreover, the point of wind load 
was the mass center of vehicle. The wind load paralleling to the direction of bodywork was negligible, and the wind load perpendicular to the bodywork was simulated. Wind speed samples are shown in Figure 1. It can be seen from Figure 2 that the power spectral density of simulated wind speed shows a high agreement with that of standard wind speed.

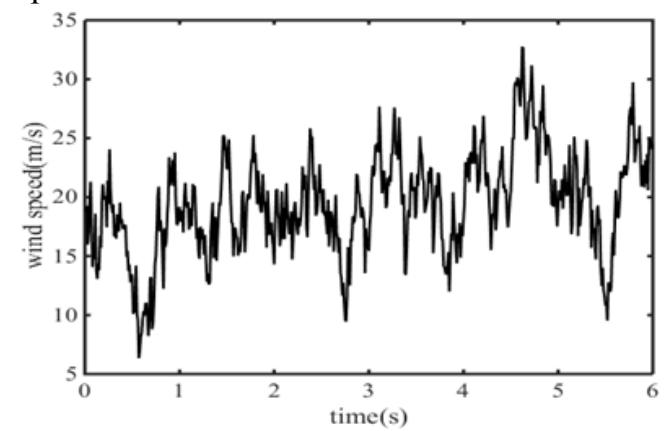

Figure 1. Samples of fluctuating wind speed

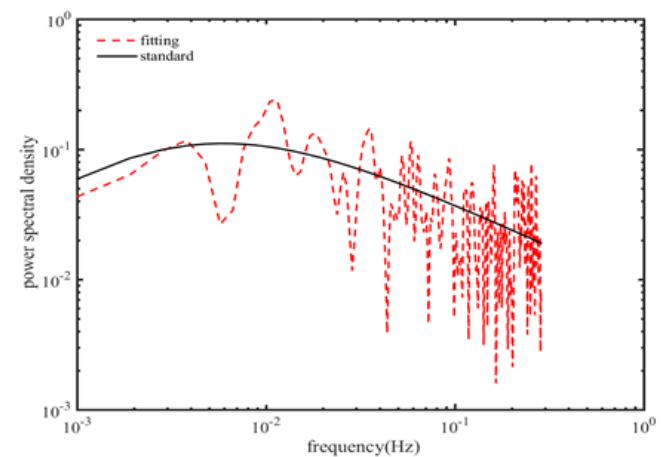

Figure 2. Comparison of power spectral density

\subsection{Road roughness}

On usual, road space frequency ranges from $0.011 \mathrm{~m}-1$ to $2.83 \mathrm{~m}-1$, and time frequency ranges from $0.44 \mathrm{~Hz}$ to $28.3 \mathrm{~Hz}$ including suspension quality natural frequency $1.0 \sim 2.0 \mathrm{~Hz}$ and non-suspension quality natural frequency $10.0 \sim 15.0 \mathrm{~Hz}$ [8]. Road roughness is divided into eight categories and $\mathrm{A}, \mathrm{B}, \mathrm{C}$ road roughness are the most common to see [9]. Three-dimensional road roughness of B level was simulated on the condition that time frequency was divided into 200 portions and sampling frequency was taken as $0.01 \mathrm{~s}$. Road roughness with $40 \mathrm{~m}$ both in width and length was simulated by sinusoid superposition method.

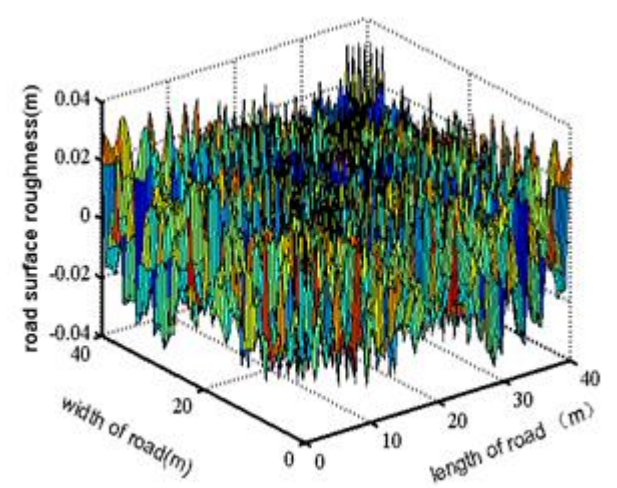

Figure 3. Road roughness generated by sinusoid superposition method

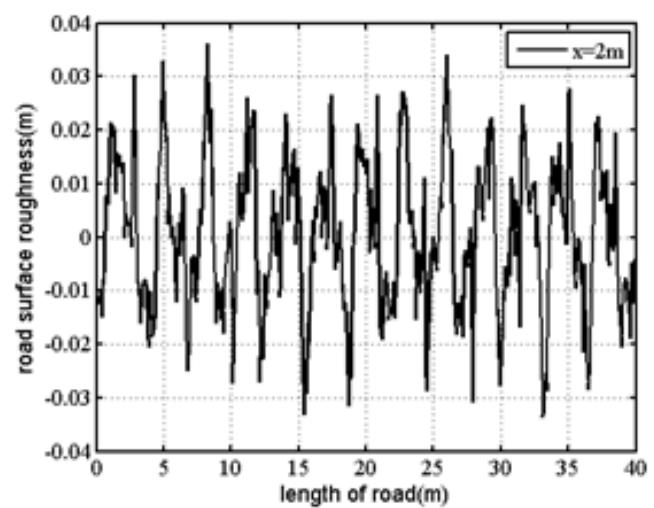

Figure 4. Roughness along the road generated by sinusoid superposition method at $2 \mathrm{~m}$ width of road

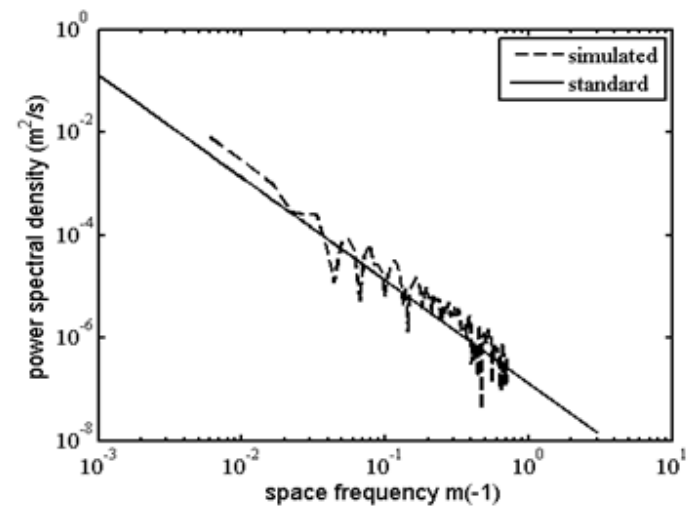

Figure 5. Simulated power spectral density by sinusoid superposition method and the standard one

Three-dimensional road roughness simulated by sinusoid superposition method is given in Figure 3 and 4. It can be seen that variation of road roughness ranged from $-0.03 \mathrm{~m}$ to $0.03 \mathrm{~m}$. Power spectral density (Figure 5) was simulated to confirm the correctness of road roughness generated by sinusoid superposition method.

\subsection{Vehicle model}

In order to establish the equation of vehicle motion, the following assumptions were made: (1) Vehicle moved in the longitudinal direction of road with constant speed, and longitudinal dynamic effects were not considered. (2) Spring constitutive models were linear. (3) Damping was viscous. (4) All vehicle units were symmetrical. (5) Vehicle units only made vibrations of small displacement [10-12].

There were five parameters in the equation of vehicle motion. The specific meaning is as follows:

\subsubsection{Displacement parameters}

The total freedom degrees for four wheels were:

$$
Z_{s 1}, Y_{s 1}, Z_{s 2}, Y_{s 2}, Z_{s 3}, Y_{s 3}, Z_{s 4}, Y_{s 4}
$$

Lateral independence freedom degrees:

$$
Y_{\mathrm{cl}}, Y_{c 2}, Y_{c 3}, Y_{c 4}
$$

Bodywork of five freedom degrees:

$$
Z_{V}, Y_{V}, \theta_{V}, \phi_{V}, \varphi_{V}
$$




\subsubsection{Quality parameters}

The 13-DOF vehicle system mass and mass inertia moment parameters were defined as follows:

Four wheels:

$$
M_{s 1}, M_{s 2}, M_{s 3}, M_{s 4}
$$

Mass at the contact site of wheel and road:

Body:

$$
M_{c 1}, M_{c 2}, M_{c 3}, M_{c 4}
$$

$$
M_{v}, J_{x v}, J_{y v}, J_{z v}
$$

Among them, M, J-represented the mass and mass moments of the units; the subscripts $x, y, z$ indicated the horizontal axis direction, the vertical axis direction, and the vertical direction, separately.

\subsubsection{Geometric parameters}

The relative positions (geometric dimensions) of various units in vehicle system model with damping elements and springs are given in Table 1.

Table 1. Geometric parameters of suspension system

\begin{tabular}{ll}
\hline Parameters & Meanings \\
\hline$L_{1}$ & $\begin{array}{l}\text { The distance from the rear axle to the mass } \\
\text { center of bodywork } \\
\text { The distance from the front axle to the } \\
L_{2}\end{array}$ \\
$b_{1}$ & $\begin{array}{l}\text { Hass center of bodywork } \\
h_{1}\end{array}$ \\
$h_{\mathrm{v}}$ & $\begin{array}{l}\text { Distance between body center and lateral } \\
\text { spring }\end{array}$ \\
\hline
\end{tabular}

\subsubsection{Stiffness parameters}

For two-axis suspension vehicle model, the stiffness parameter consisted both of the upper $(u)$ and the lower $(l)$ suspension systems.

Upper suspension system:

$$
K_{u z 1}, K_{u z 2}, K_{u z 3}, K_{u z 4}, K_{u y 1}, K_{u y 2}, K_{u y 3}, K_{u y 4}
$$

Lower suspension system:

$$
K_{l z 1}, K_{l z 2}, K_{l z 3}, K_{l z 4}, K_{l y 1}, K_{l y 2}, K_{l y 3}, K_{l y 4}
$$

\subsubsection{Damping parameters}

Damping parameters corresponding to the stiffness parameters of suspension system:

Upper suspension system:

$$
C_{u z 1}, C_{u z 2}, C_{u z 3}, C_{u z 4}, C_{u y 1}, C_{u y 2}, C_{u y 3}, C_{u y 4}
$$

Lower suspension system:

$$
C_{l z 1}, C_{l z 2}, C_{l z 3}, C_{l z 4}, C_{l y 1}, C_{l y 2}, C_{l y 3}, C_{l y 4}
$$

\section{Safety analysis}

\subsection{Initial conditions}

The wind direction and the driving direction were assumed to be vertical, and at this point, the external excitation of the vehicle included road surface roughness and wind load. The moment when the vehicle started to experience road surface friction was $0.0 \mathrm{~s}$. When analyzing the sudden wind load, firstly, the vehicle travelled in a windless area for $6.0 \mathrm{~s}$. Within $6.0 \sim 6.5 \mathrm{~s}$, the average wind speed was input in program, and wind speed samples were generated. The force was added to the bodywork. When studying the influences of pulsating wind, different wind speeds and vehicle speeds, the road surface roughness and wind load excitations were given at the same time in $0.0 \mathrm{~s}$. In this article, whether an accident occurs or not was assessed according to Baker's vehicle accident criteria [13-15].

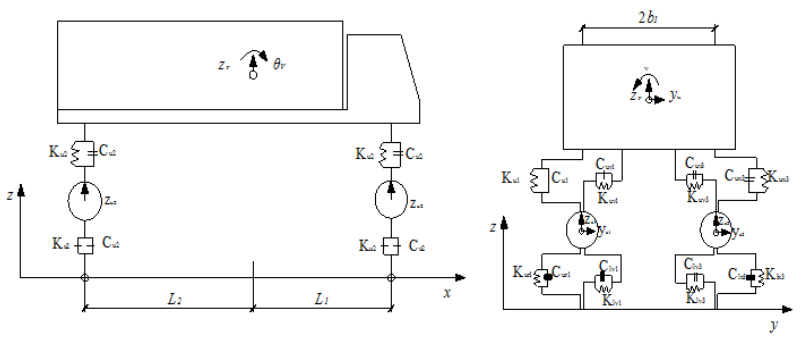

Figure 6. Two axis vehicle vibration model

\subsection{Influences of gusts}

The vehicle speed was $60.0 \mathrm{~km} / \mathrm{h}$, and the average wind speed was $20.0 \mathrm{~m} / \mathrm{s}$. The road surface roughness ranked Grade B, and the time integration step in the program was $0.01 \mathrm{~s}$, at the same time, the air density was $1.29 \mathrm{~kg} / \mathrm{m}^{3}$. The vertical displacement and lateral displacement of vehicle driving in the absence of wind for $6.5 \mathrm{~s}$ are shown in Figure 7. The vertical displacement and lateral displacement of vehicle driving in the absence of wind for $6.0 \mathrm{~s}$ and followed by $0.5 \mathrm{~s}$ in sudden gust are shown in Figure 8.

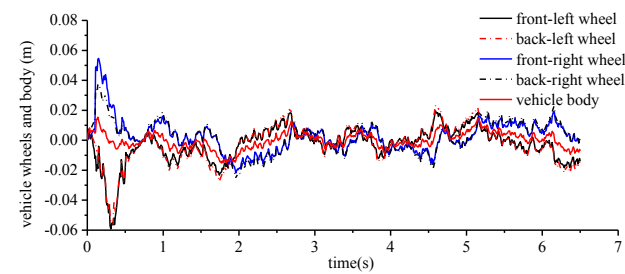

(a) Vertical displacement

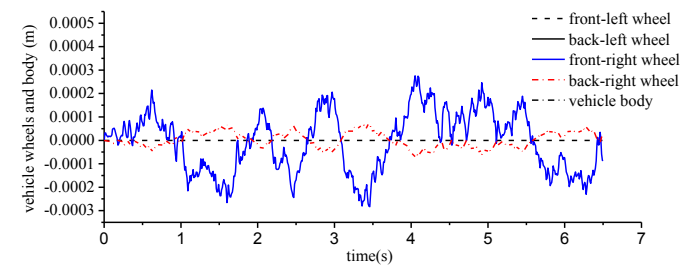

(b) Lateral displacement

Figure 7. Displacement of vehicle without gust

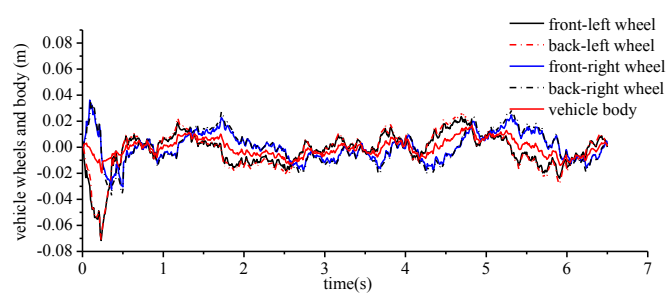

(a) Vertical displacement 


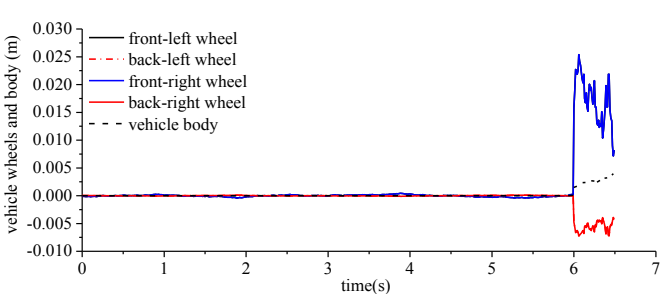

(b) Lateral displacement

Figure 8. Displacement of vehicle with gust

The followings can be derived from Figure 7 and Figure 8. (1) No matter there is gust or not, the responses of vehicle to sudden change are all completed within 1.0 $\mathrm{s}$. The excitation inputs of three-dimensional road surface roughness to the wheels on right and left sides are different, so the vertical displacement curve of right wheels is different from that of left wheels. (2) Under Grade B of road surface roughness, the vertical displacement range of wheels after stability is $-0.03 \sim 0.04$ m. (3) The vertical displacement range of bodywork is $0.01 \sim 0.02 \mathrm{~m}$. The vertical displacement ranges of bodywork and wheels in Figure 7(a) and Figure 8(a) are consistent, so the vertical displacements are basically not affected by gust. (4) There are only three lateral displacement curves in Figure 7(b) and Figure 8(b). The front left and right wheels as well as the rear left and right wheels are both coincident. This result accords with the assumption in the establishment of vehicle motion equation that the connection between the left and right wheels is rigid, which illuminates that the procedure runs correctly. (5) Without wind, the lateral displacement of wheels is tiny and fluctuates within $0 \sim 0.2 \mathrm{~mm}$. The lateral displacement changes of bodywork are at the magnitude of 10-22 $\mathrm{m}$ that can be ignored, hence there was no lateral deviation of bodywork. (6) The vehicle experienced gust in 6th second, and it can be seen from Figure 8(b) that the lateral displacement of bodywork took place within the next $0.5 \mathrm{~s}$. In Baker's accident model, this offset is the cause of a side-slip accident. Under this operating condition, the cumulative displacement of bodywork within $0.5 \mathrm{~s}$ was $0.132 \mathrm{~m}$, and $0.5 \mathrm{~m}$ is the limit of sideslip. It can thus be seen that no sideslip accident happened.

\section{Discussion}

In this study, the wind-vehicle-road system was established. It is found that the vertical displacement of a vehicle body will not generally be affected under the action of gusts. However, the lateral deviation of the body will occur, which is the direct cause of a sliding accident. Wang et al. [16] built a road vehicle-bridgewind (RVBW) system and found that vehicles entering a sharp crosswind gust would have a significant risk of overturning, while the focus of the research was the impact of tower and bridge dynamic response on vehicles. Moreover, William et al. [17] indicated that the probability of overturning accidents was relatively high in various kinds of wind-induced vehicle accidents. In another study [18], it was manifested that the lift oscillations of high sided road vehicles were dominated by the large scale instability caused by wake vortices. In this paper, the data shows that the contact force on the rear wheel of windward side is minimal and the wheel is easy to get off the ground, which decides whether a rollover accident happens or not. This provides a reference for the future studies on the more accurate safety thresholds.

\section{Conclusion}

In order to assess the safety of transportation vehicles carrying prefabricated units under the action of gusts, the roughness of road surfaces was simulated by the sinusoid superposition method, and the wind load was simulated by the harmonic synthesis method. The analysis model of the 13-DOF vehicle was established, and the windvehicle-road system was formed. Additionally, the safety of transportation vehicles was analyzed with the relevant parameters. The results of this study are summarized as follows.

When a vehicle encounters a sudden gust during driving, the vertical displacements of its body and wheels are basically not influenced, but lateral deviation of the body will occur. The deviation will augment as the wind speed increases, and this is the direct cause of a sideslip accident. When the body is subjected to sudden gusts, the contact force on the left (lee) side wheel will rise, while the one on the right (windward) side wheel will drop. Therefore, it can be assumed that the contact force on the rear wheel of windward side is minimal and the wheel is easy to get off the ground, which decides whether a rollover accident happens or not.

In this article, the wind-vehicle-road system was formed, and the safety of transportation vehicles was analyzed with fixed parameters. However, the working conditions considered in this study are limited. Other impact parameters and safety thresholds need further study.

\section{Acknowledgment}

This study is financially supported by the national 13th five-year key research and development program of China (2016YFC0701909-1), Fundamental Research Funds for the Central Universities (106112017CDJXY200009, 106112016CDJRC000101).

\section{References}

1. S.Q. Wu, S.S. Law, Vehicle axle load identification on bridge deck with irregular road surface profile. Eng. Struc., 33, 591-601(2011)

2. H. Kozmar, K. Butler et al., Downslope gusty wind loading of vehicles on bridges. J. Bridge Eng., 20(11), 04015008(2015)

3. R.N. Meroney, R. Derickson, Virtual reality in wind engineering: the windy world within the computer. J. Wind Eng., 11(2), 11-26(2014) 
4. B. Blocken, 50 years of Computational Wind Engineering: Past, present and future. J. Wind Eng. Ind. Aerodyn., 129, 69-102(2015)

5. D.G. Vernay, B. 1. Raphae, I.F.C. Smith, Improving simulation predictions of wind around buildings using measurements through system identification techniques. Build. Environ., 94(2), 620-631(2015)

6. Y Tominaga, Flow around a high-rise building using steady and unsteady RANS CFD: Effect of largescale fluctuations on the velocity statistics. J. Wind Eng. Ind. Aerodyn., 142, 93-103(2015)

7. P. Patlakas, G. Galanis, N Barranger, Extreme wind events in a complex maritime environment: Ways of quantification. J. Wind Eng. Ind. Aerodyn., 149, 89101(2016)

8. P.F. Li, S.G. Feng, X.L. Deng, Three-dimensional virtual road's harmonic reconstruction. Auto Engnieer, 11(8), 24-27(2014)

9. K. Bogsjö, K. Podgórski, I. Rychlik, Models for road surface roughness. Vehicle System Dynamics, 50(5), 725-747(2012)

10. H.L. Zhang, W.Q. Yang, Evaluation method of pavement roughness based on 5-DOF humanvehicle- road vibration model. Journal of Traffic and Transportation Engneering, 10(4), 16-22(2010)

11. M. Agostinacchio, D. Ciampa, S. Olita, The vibrations induced by surface irregularities in road pavements-a Matlab approach. Europe Transportation Research Review, 11(6), 267275(2014)
12. A. Pazooki, S. Rakheja, D. Cao, Modeling and validation of off-road vehicle ride dynamics. Mechanical Systems and Signal Processing, 28, 679695(2012)

13. C.J. Baker, J. Jones, F. Lopez-Calleja et al., Measurements of the cross wind forces on trains. J. Wind Eng. Ind. Aerodyn., 92, 547-563(2004)

14. C.J. Baker, S. Reynolds, Wind-induced accidents of road vehicles. Accident Analysis \& Prevention, 24(6), 559-575(1992)

15. M. Sterling, A.D. Quinn, D.M. Hargreaves, et al. A comparison of different methods to evaluate the wind induced forces on a high sided lorry. J. Wind Eng. Ind. Aerodyn., 98, 10-20(2010)

16. B. Wang, Y.L. Xu, Safety analysis of a road vehicle passing by a bridge tower under crosswinds. J. Journal of Wind Engineering and Industrial Aerodynamics; Journal of Wind Engineering \& Industrial Aerodynamics, 137, 25-36(2015)

17. Y. William, W. Oraby, S. Metwally, Analysis of Vehicle Lateral Dynamics due to Variable Wind Gusts. J. SAE International Journal of Commercial Vehicles, 7(2), 666-674(2014)

18. S.A. Coleman, C.J. Baker, D.M. Hargreaves et al., 1994. An experimental study of the aerodynamic behaviour of high sided lorries in cross winds. J. Journal of Wind Engineering and Industrial Aerodynamics, 53(3), 401-429(1994) 